\title{
Desain Media Pembelajaran Berbasis Daring Memanfaatkan PortalSchoology pada Pembelajaran Apresiasi Sastra
}

\author{
Oleh \\ Achmad Yuhdi dan Nadra Amalia ${ }^{2}$ \\ (achmadyuhdi@gmail.com) \\ Dosen Program Studi Pendidikan Bahasa dan Sastra Indonesia \\ Universitas Muhammadiyah Sumatera Utara
}

\begin{abstract}
Abstrak
Proses pembelajaran di era digital saat ini tak lepas dari teknologi informasi internet. Berbagai program aplikasi/ portale learning ditawarkan,mulai dari berbayar hingga gratis. Tulisan ini bertujuan untuk mendeskripsikan desain media pembelajaran memanfaatkan salah satu portal e learning yang tidak berbayar, yakni schoology. Schoology membantu dosen dalam membuka kesempatan komunikasi yang luas kepada mahasiswa agar mahasiswa dapat lebih mudah untuk mengambil peran/bagian dalam diskusi dan kerja sama dalam tim. Selain itu, Schoology juga mempunyai banyak ciri dan fungsi yang menarik untuk dimanfaatkan oleh mahasiswa. Schoology juga didukung oleh berbagai bentuk media seperti video, audio dan imge yang dapat menarik minat belajar mahasiswa. Schoology mengarahkan mahasiswa mengaplikasikan penggunaan tekonologi dalam pembelajaran.
\end{abstract}

Kata Kunci: media internet, e learning, schoology

\section{Pendahuluan}

Perkembangan teknologi informasi dan komunikasi telah membawa perubahan yang sangat besar bagi kemajuan dunia pendidikan. Seiring dengan perkembangan tersebut metode pembelajaran juga banyak mengalami perkembangan, baik metode pembelajaran secara personal, media pembelajaran ataupun proses pembelajaran. Bentuk dari perkembangan teknologi informasi yang diterapkan di dunia pendidikan adalah e-learning. Pembelajaran berbasis internet/E-Learning merupakan sebuah inovasi yang mempunyai kontribusi sangat besar terhadap perubahan proses pembelajaran, dimana proses belajar tidak lagi hanya mendengarkan uraian materi dari dosen tetapi mahasiswa juga melakukan aktivitas lain seperti mengamati, melakukan, mendemonstrasikan dan lain-lain.

Pemanfaatan teknologi dalam pembelajaran merupakan kegiatan wajib yang dilaksanakan dosen pada era digitaliasi saat ini. Pemanfaatan teknologi informasi dan komunikasi untuk pendidikan dapat dilaksanakan dalam berbagai bentuk sesuai dengan fungsinya dalam pendidikan. Fungsi teknologi informasi dan Pemanfaatan teknologi informasi dan komunikasi (TIK) untuk pendidikan sudah menjadi keharusan yang tidak dapat 
ditunda-tunda lagi. Berbagai aplikasi teknologi informasi dan komunikasi sudah tersedia dalam masyarakat dan sudah siap menanti untuk dimanfaatkan secara optimal untuk keperluan pendidikan. Pada kondisi riil, teknologi informasi dan komunikasi dalam pendidikan nantinya berfungsi sebagai gudang ilmu, alat bantu pembelajaran, fasilitas pendidikan, standar kompetensi, penunjang administrasi, alat bantu manajemen sekolah, dan sebagai infrastruktur pendidikan.

Kurikulum KKNI yang sudah diberlakukan di perguruan tinggi sejak tahun 2015 telah mengubah paradigma pendidikan yang selama ini pengajaran berpusat pada dosen menjadi pengajaran yang berpusat kepada mahasiswa. Perubahan paradigma kurikulum dan pembelajaran tersebut setelah diterbitkannya kurikulum KKNI dan Standar Nasional Dikti tahun 2015 merupakan hal yang harus diperhatikan secara seksama oleh civitas akademika. Pemahaman civitas akademika terhadap perubahan paradigma pembelajaran pada KKNI yang menitikberatkan pada student based learning perlu menjadi perhatian bersama agar tujuan Krikulum KKNI tersebut dapat tercapai.Tentunya, e-learning merupakan salah satu bentuk kegiatan pembelajaran yang mencirikan student based learning tersebut.

Rusman (2012:291) menjelaskan ahwa pembelajaran berbasis web merupakan suatu kegiatan pembelajaran yang memanfaatkan media situs (website) yang bisa diakses melalui jaringan internet. Pembelajaran berbasis web atau yang dikenal juga dengan "web based learning" merupakan salah satu jenis penerapan dari pembelajaran elektronik (e-learning). Salah satu platform yang dapat digunakan sebagai media pembelajaran interaktif ialah Schoology. Schoology merupakan salah satu laman web yang berbentuk web sosial yang mana ia menawarkan pembelajaran sama seperti di dalam kelas secara percuma dan mudah digunakan seperti Facebook. Schoology membantu dosen dalam membuka kesempatan komunikasi yang luas kepada mahasiswa agar mahasiswa dapat lebih mudah untuk mengambil peran/bagian dalam diskusi dan kerja sama dalam tim. Selain itu, Schoology juga mempunyai banyak ciri dan fungsi yang menarik untuk dimanfaatkan oleh mahasiswa. Schoology juga didukung oleh berbagai bentuk media seperti video, audio dan imge yang dapat menarik minat siswa. Schoology mengarahkan mahasiswa mengaplikasikan penggunaan tekonologi dalam pembelajaran.

E-learning dengan schoology dapat memberikan pengalaman belajar yang menarik bagi mahasiswa dengan membentuk iklim ilmiah yang disesuaikan terhadap materi pembelajaran yang menarik. Aktivitas mahasiswa didukung dengan suasana belajar yang kompetitif, studi kasus yang menantang dan memacu belajar, pembentukan forum-forum 
diskusi ilmiah, penciptaan topik-topik penelitian, dan sistem penilaian yang memotivasi peserta didik untuk belajar. Mahasiswa juga mendapatkan feedback berupa komentar tentang aktivitas, penjelasan yang kurang dari dosen sehingga peserta didik mendapatkan informasi dari seorang dosen secara langsung.

Pembelajaran apresiasi sastra Indonesia merupakan mata kuliah wajib di Prodi Pendidikan Bahasa dan Sastra Indonesia pada perguruan tinggi manapun di Indonesia. Beberapa perguruan tinggi ada yang membagi ke dalam tiga genre sastra, yakni puisi, prosa dan drama, danada juga yang menyatukan ketiganya dalam satu mata kuliah apresiasi sastra Indonesia. Tentunya dalam mata kuliah apresiasi sastra Indonesia ini diperlukan usaha yang tekun dari mahasiswa dalam membaca karya sastra menuju tingkatan apresiasi.

Kemampuan apresiasi sastra pada mahasiwa dibentuk melalui kebiasaan membaca karya sastra sejak mereka menjadi siswa di sekolah menengah. Akan tetapi, tingkat kebiasaan membaca siswa saat ini sangat rendah. Jika diminta untuk memberi pendapat terhadap buku yang dibaca, saat ini tanpa membaca buku siswa sudah mampu memberikan pendapat atas informasi buku tersebut melalui internet.

Saat mengikuti kegiatan Siswa Bertanya Sastrawab Bicara (SBSB) tahun 2003 di Medan, Taufik Ismail, penyair Indonesia, menyampaikan hasil penelitianya kepada seluruh peserta yang hadir. Diutarakannya, dia memberikan pertanyaan kepada sekitar 100 responden yang tingkat pendidikannya minimal Sekolah Menengah Umum (SMU) di negara maju, seperti Amerika Serikat, Kanada, dan Eropa. Diperoleh jawaban jika dalam seminggu mereka menamatkan membaca satu buku, baik novel, antologi cerpen, puisi, atau kumpulan essai, dan lainnya. Tidak hanya itu, para responden juga mengatakan jika mereka diwajibkan membuat resensi atau pendapat terhadap isi buku yang dibacanya dalam bentuk tulisan. Diperoleh data, dalam setahun masyarakat di negara maju itu "menghabiskan" minimal sekitar 30 buku. Dalam catatan Taufik Ismail, ada responden yang bersekolah sejak SD telah dibudayakan untuk membaca buku dan menuliskan pendapatnya tentang buku yang dibacanya. Jika dikaji secara matematika, selama enam tahun seorang siswa sekolah di tingkat menengah (SMP dan SMU), maka minimal mereka sudah membaca 180 buku dan sedikitnya mereka telah menghasilkan karya tulis berupa pendapatnya atas buku bacaanya sebanyak 180 pula.Hal ini tentu sangat berbeda dengan keadaan siswa di Indonesia.

Beberapa penjelasan di atas merupakan masalah yang dihadapi oleh pengajar sastra berkenaan dengan kebiasaan membaca. Dari semua uraian di atas, pembahasan dalam tulisan ini akan difokuskan pada hal-hal berikut: 
(1) Pembelajaran apresiasi sastra pada kurikulum 2013, dan

(2) Desain pembelajaran apresiasi sastra berbasis internet

\section{Pembelajaran Apresiasi Sastra pada Kurikulum 2013}

Menurut Andayani (2009:69) Pembelajaran apresiasi sastra berhubungan dengan kegiatan yang ada keterkaitan dengan karya sastra, yaitu mendengar atau membaca karya sastra dengan penghayatan dan menulis sastra. Pembelajaran apresiasi sastra memperkenalkan kepada peserta didik nilai-nilai yang didukung karya sastra dan mengajak peserta didik ikut menghayati pengalaman-pengalaman yang disajikan.

Pembelajaran apresiasi sastra bertujuan membawa peserta didik ke arah pengalaman sastra. Hal ini sejalan dengan pernyataaan Sumardi (mengutip pendapat Oemarjati) bahwa tujuan pembelajaran apresiasi sastra, yaitu menanamkan, menumbuhkan, dan mengembangkan kepekaan terhadap masalah manusia, pengenalan, dan rasa hormat terhadap tata nilai, baik secara individual maupun sosial (1997: 168-198). Oleh karena itu, diperlukan strategi-strategi agar siswa dapat mengapresiasi karya sastra.

Pembelajaran apresiasi sastra sebaiknya tidak mengarah pada pengetahuan tentang teori sastra saja, tetapi harus melibatkan siswa secara langsung dalam proses mengapresiasi. Guru hendaknya memberi kesempatan kepada siswa untuk mendapatkan sendiri kenikmatan terhadap sastra sehingga siswa dapat membaca, mengenali, memahami, menghayati, menilai, dan akhirnya menghargai karya sastra.

Pembelajaran sastra di Sekolah Menengah Pertama (SMP) dan Sekolah Menengah Atas (SMA) merupakan pembelajaran yang sangat penting peranannya untuk membentuk daya nalar siswa dan mengenalkan sastra sebagai salah satu bentuk kebudayaan di Indonesia kepada para siswa. Namun, ada beberapa hal penting yang harus dicermati ulang dalam pembelajaran sastra di sekolah mengingat sastra masuk ke dalam bagiannya dengan menggunakan acuan kurikulum yang diberlakukan saat ini.

Kurikulum 2013 edisi revisi 2017 saat ini sudah menyahuti kritik dari pengamat pendidikan sastra terkait dengan konten materi ajar sastra yang diberikan. Pada awal diresmikannya kurikulum 2013 materi ajar sastra hanya menjadi pelengkap dalam kurikulum. Materi ajar sastra kurikulum 2013 untuk tingkat sekolah menengah atas hanya ada pada kelasXI danXII saja.Pertimbangan yang dianut, mungkin penggunaan bahasa lebih dominan dalam kehidupan. Penjelasan berikut ini akan mengkaji posisi materi ajar apresiasi sastra pada tingkat sekolah menengah atas kurikulum 2013 edisi revisi 2017. Kurikulum 2013 telah menentukan kompetensi yang harus dimiliki para siswa setelah mengikuti proses pembelajaran tertentu. Kajian diarahkan pada hubungan antara kompetensi inti dan standar kompetensi dan prediksi materi ajar yang dapat mendukung terhadap teraksannya tujuan kurikulum khusus materi ajar ajar sastra. Adapun materi ajar apresiasi sastra dalam 
kurikulum 2013 disajikan di bawah ini dalam bentuk tabel materi ajar sastra untuk SMA/SMK/Sederajat.

Tabel 1

Materi Ajar Apresiasi Sastra

\begin{tabular}{|c|c|}
\hline Kompetensi Inti & Kompetensi Dasar \\
\hline \multicolumn{2}{|c|}{ Kelas X } \\
\hline \multirow{5}{*}{$\begin{array}{l}\text { 3. Memahami, menerapkan, menganalisis } \\
\text { pengetahuan faktual, konseptual, prosedu- } \\
\text { ral berdasarkan rasa ingin tahunya tentang } \\
\text { ilmu pengetahuan, teknologi, seni, budaya, } \\
\text { dan humaniora dengan wawasan kemanu- } \\
\text { siaan, kebangsaan, kenegaraan, dan pera- } \\
\text { daban terkait penyebab fenomena dan } \\
\text { keja-dian, serta menerapkan pengetahuan } \\
\text { prose-dural pada bidang kajian yang } \\
\text { spesifik sesuai dengan bakat dan minatnya } \\
\text { untuk memecahkan masalah. }\end{array}$} & $\begin{array}{l}\text { 3.7 Mengidentifikasi nilai-nilai dan isi yang } \\
\text { terkandung dalam cerita rakyat (hikayat) baik } \\
\text { lisan maupun tulis. }\end{array}$ \\
\hline & $\begin{array}{l}3.8 \text { Membandingkan nilai-nilai dan kebahasaan } \\
\text { cerita rakyat dan cerpen }\end{array}$ \\
\hline & $\begin{array}{l}\text { 3.9 Mengidentifikasi butir-butir penting dari dua } \\
\text { buku nonfiksi (buku pengayaan) dan satu novel } \\
\text { yang dibacakan nilai-nilai dan kebaha-saan cerita } \\
\text { rakyat dan cerpen. }\end{array}$ \\
\hline & 3.17 Menganalisis unsur pembangun puisi \\
\hline & $\begin{array}{l}\text { 3.18 Menganalisis isi dari minimal satu buku fiksi } \\
\text { dan satu buku nonfiksi yang sudah dibaca }\end{array}$ \\
\hline \multirow{4}{*}{$\begin{array}{l}\text { 4. Mengolah, menalar, menyaji, dan } \\
\text { mencipta dalam ranah konkret dan ranah } \\
\text { abstrak terkait dengan pengembangan dari } \\
\text { yang dipelajarinya di sekolah secara } \\
\text { mandiri serta bertindak secara efektif dan } \\
\text { kreatif, dan mampu menggunakan metoda } \\
\text { sesuai kaidah keilmuan }\end{array}$} & $\begin{array}{l}4.7 \text { Menceritakan kembali isi cerita rakyat } \\
\text { (hikayat) yang didengar dan dibaca }\end{array}$ \\
\hline & $\begin{array}{l}\text { 4.8 Mengembangkan cerita rakyat (hikayat) ke } \\
\text { dalam bentuk cerpen dengan memerhatikan isi } \\
\text { dan nilai-nilai. }\end{array}$ \\
\hline & $\begin{array}{l}4.9 \text { Menyusun ikhtisar dari dua buku nonfiksi } \\
\text { (buku pengayaan) dan ringkasan dari satu novel } \\
\text { yang dibaca. }\end{array}$ \\
\hline & $\begin{array}{l}\text { 4.17 Menulis puisi dengan memerhatikan unsur } \\
\text { pembangunnya (tema, diksi, gaya bahasa, imaji, } \\
\text { struktur, perwajahan) }\end{array}$ \\
\hline \multicolumn{2}{|c|}{ Kelas XI } \\
\hline \multirow{6}{*}{$\begin{array}{l}\text { 3. Memahami, menerapkan, menganalisis } \\
\text { pengetahuan faktual, konseptual, prosedu- } \\
\text { ral berdasarkan rasa ingin tahunya tentang } \\
\text { ilmu pengetahuan, teknologi, seni, budaya, } \\
\text { dan humaniora dengan wawasan kemanu- } \\
\text { siaan, kebangsaan, kenegaraan, dan pera- } \\
\text { daban terkait penyebab fenomena dan } \\
\text { keja-dian, serta menerapkan pengetahuan } \\
\text { prose-dural pada bidang kajian yang } \\
\text { spesifik sesuai dengan bakat dan minatnya } \\
\text { untuk memecahkan masalah. }\end{array}$} & $\begin{array}{l}\text { 3.7 Mengidentifikasi butir-butir penting dari satu } \\
\text { buku pengayaan (nonfiksi) yang dibaca. }\end{array}$ \\
\hline & $\begin{array}{l}\text { 3.8 Mengidentifikasi nilai-nilai kehidupan yang } \\
\text { terkandung dalam kumpulan cerita pendek yang } \\
\text { dibaca. }\end{array}$ \\
\hline & $\begin{array}{l}\text { 3.9 Menganalisis unsur-unsur pembangun cerita } \\
\text { pendek dalam buku kumpulan cerita pendek. }\end{array}$ \\
\hline & $\begin{array}{l}3.18 \text { Mengidentifikasi alur cerita, babak demi } \\
\text { babak, dan konflik dalam drama yang dibaca atau } \\
\text { ditonton. }\end{array}$ \\
\hline & $\begin{array}{l}\text { 3.19 Menganalisis isi dan kebahasaan drama yang } \\
\text { dibaca atau ditonton. }\end{array}$ \\
\hline & $\begin{array}{l}3.20 \text { Menganalisis pesan dari dua buku fiksi } \\
\text { (novel dan buku kumpulan puisi) yang dibaca. }\end{array}$ \\
\hline \multirow{3}{*}{$\begin{array}{l}\text { 4. Mengolah, menalar, menyaji, dan } \\
\text { mencipta dalam ranah konkret dan ranah } \\
\text { abstrak terkait dengan pengembangan dari } \\
\text { yang dipelajarinya di sekolah secara } \\
\text { mandiri serta bertindak secara efektif dan } \\
\text { kreatif, dan mampu menggunakan metoda }\end{array}$} & $\begin{array}{l}\text { 4.7 Menyusun laporan butir-butir penting dari satu } \\
\text { buku pengayaan (nonfiksi }\end{array}$ \\
\hline & $\begin{array}{l}4.8 \text { Mendemonstrasikan salah satu nilai kehidupan } \\
\text { yang dipelajari dalam cerita pendek }\end{array}$ \\
\hline & $\begin{array}{l}4.9 \text { Mengkonstruksi sebuah cerita pendek dengan } \\
\text { memerhatikan unsur-unsur pembangun cerpen }\end{array}$ \\
\hline
\end{tabular}



dengan memerhatikan isi dan kebahasaan

\section{Kelas XII}

3. Memahami, menerapkan, menganalisis pengetahuan faktual, konseptual, prosedural berdasarkan rasa ingin tahunya tentang ilmu pengetahuan, teknologi, seni, budaya, dan humaniora dengan wawasan kemanusiaan, kebangsaan, kenegaraan, dan peradaban terkait penyebab fenomena dan kejadian, serta menerapkan pengetahuan prosedural pada bidang kajian yang spesifik sesuai dengan bakat dan minatnya untuk meme-cahkan masalah.

4. Mengolah, menalar, menyaji, dan mencipta dalam ranah konkret dan ranah abstrak terkait dengan pengembangan dari yang dipelajarinya di sekolah secara mandiri serta bertindak secara efektif dan kreatif, dan mampu menggunakan metoda sesuai kaidah keilmuan

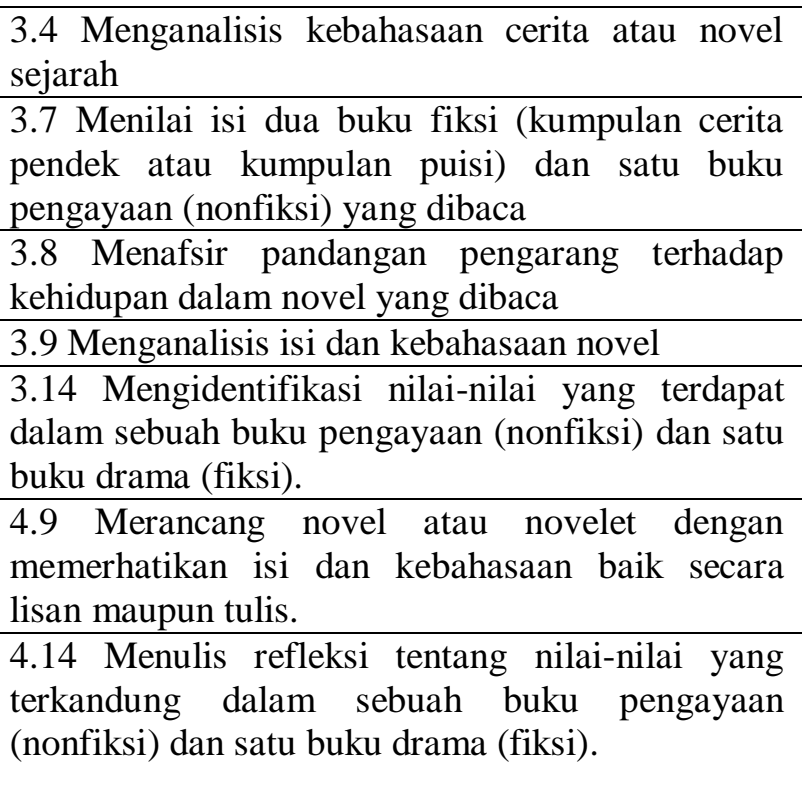

Kurikulum 2013 lebih menekankan pada pembentukan sikap/afektif. Untuk pembentukan sikap ini, hanya aspek-aspek seni yang mampu menjangkaunya. Sikap hanya akan terjangkau dengan seni, termasuk di dalamnya seni berbahasa yaitu sastra. Karena itu, aspek sastra menjadi sesuatu yang mutlak disuguhkan kepada generasi muda melalui pendidikan. Kehadiran kurikulum 2013 edisi revisi 2017 ini, sebagaimana yang dimuat pada tabel di atas, telah memuat konten pembelajaran sastra yang sesuai dengan porsinya. Bila dicermati, aspek apresiasi sastra juga telah dimuat pada kompetensi dasar. Melalui konten tersebut, selanjutnya diperlukan peran guru bahasa dan sastra Indonesia untuk memiliki kompetensi sastra yang baik. Melalui guru-guru yang kreatif, inovatif dan imajinatif, materi ajar sastra Indonesia yang dimuat kurikulum menjadi sangat bermakna.

Inovasi pembelajaran sastra pada era digital saat ini selalu dikaitkan dengan internet. Berbagai inovasi pembelajaran ditawarkan melalui media internet tersebut. Penggunaan Internet untuk keperluan pendidikan yang semakin meluas terutama di negara-negara maju, merupakan fakta yang menunjukkan bahwa dengan media ini memang dimungkinkan diselenggarakannya proses belajar mengajar yang lebih efektif. Salah satu portal e learning tersebut dapat dikembangkan dengan memanfaatkan schoology.

E-learning dengan schoology dapat memberikan pengalaman belajar yang menarik bagi peserta didik dengan membentuk iklim ilmiah yang disesuaikan terhadap materi pembelajaran yang menarik. Aktivitas peserta didik didukung dengan suasana belajar yang kompetitif, studi kasus yang menantang dan memacu belajar, pembentukan forum-forum 
diskusi ilmiah, penciptaan topik-topik penelitian, dan sistem penilaian yang memotivasi peserta didik untuk belajar. Peserta didik juga mendapatkan feedback berupa komentar tentang aktivitas, penjelasan yang kurang dari guru/dosen sehingga peserta didik mendapatkan informasi dari seorang guru/dosen secara langsung.

Beberapa studi penelitian telah menemukan bahwa blended learning dapat meningkatkan hasil belajar sama dengan atau lebih tinggi dari mahasiswa yang belajar secara konvensional atau sepenuhnya online, meskipun tingkat keberhasilan bervariasi antara disiplin ilmu (Heinze, 2008, p.35). Penelitian serupa juga menunjukkan peningkatan keaktifan mahasiswa dalam mengikuti perkuliahan pernah dilakukan Sarah dan Handaru Jati (2015:74). Hasil penelitiannya menunjukkan bahwa terdapat perbedaan motivasi belajar mahasiswa antara pembelajaran model blended learning dengan pembelajaran konvensional sebesar 5,782 dan terdapat perbedaan tingkat pemahaman sebesar 9,935.

\section{Desain Pembelajaran Apresiasi Sastra Berbasis Internet Melalui Portal Schoology}

Pengertian Schoology menurut Tugiyo Aminoto dan Hairul Pathoni (2014: 21) merupakan website yang memadu e-learning dan jejaring sosial. Konsepnya sama seperti edmodo, namun Schoology mempunyai banyak kelebihan. Membangun elearning dengan Schoology juga lebih menguntungkan bila dibandingkan dengan menggunakan moodle, yaitu karena tidak memerlukan hosting dan pengelolaan Schoology (lebih user friendly). Tentu fiturnya tidak selengkap moodle, namun untuk pembelajaran e-learning sudah sangat memadai. Fitur-fitur yang dimiliki Schoology adalah sebagai berikut: Courses, Group, Discussion, Resources, Quiz, Attendance, dan Analytics.

Terdapat tiga cara untuk login ke akun Schoology, antara lain: a. Basic, terdiri dari: (1) Instruktur, sign up untuk pemilik akun Schoology. (2) Siswa/Mahasiswa, memerlukan sebuah akses kode yang disediakan oleh guru/ dosen. (3) Orang tua, memerlukan sebuah akses kode yang disediakan oleh guru/dosen,dan b. Enterprise, untuk sebuah institusi atau sekolah yang mengelola guru dan pembelajaran dengan fungsional dan administrasi pendidikan.

Adapun menu-menu yang terdapat dalam aplikasi Schoology antara lain: a)Courses, dengan menu courses, pengguna dapat membuat kelas baru, bergabung dengan kelas yang sebelumnya sudah ada atau browsing melalui daftar kelas yang telah ditetapkan. b)Groups, berfungsi seperti pesan dinding di mana anggota grup juga dapat mem-posting pesan dinding. Ketika bergabung dengan sebuah grup, pengguna dapat mencari bagian dari grup yang pengguna inginkan. c)Resources, untuk menjaga, melacak dokumen, file, dan gambar yang pengguna upload dalam kelas.d)Recent Activity, untuk menampilkan berita terbaru yang 
terdapat pada akunSchoology. Kita dapat memposting dan meng-update dalam akun serta memilih halaman mana yang akan pengguna posting. e.) Calendar, untuk menampilkan halaman kalender yang telah diposting sebelumnya di Recent Activity.f)Messages, untuk mengirimkan pesan atau melihat pesan antara sesama pengguna Schoology, dan g)People, untuk dapat melihat daftar pengguna dalam suatu kelas.

Berdasarkan menu-menu yang terdapat dalam aplikasi schoology sebagaimana dijelaskan di atas, maka langkah-langkah mendesain media pembelajaran dapat ditempuh dengan cara berikut:

a. Membuat Course

Pada schoology course bisa kita samakan sebagai mata kuliah/mata pelajaran, oleh karena itu langkah pertama untuk melakukan proses belajar mengajar pada schoology adalah membuat course.Sectionname biasanya digunakan untuk membuat Kelas, misalnya saja anda mengajar 1 mata kuliah yang sama pada beberapa kelas yang berbeda. Dengan menggunakan sectionpengajar akan dimudahkan untuk mencopy seluruh materi, tugas maupun ujian yang sudah anda buat pada kelas A misalnya ke kelas B tanpa harus membuat atau mengupload dari awal lagi.

b. Menggunakan Accsess Code

Sebagai student atau mahasiswa,untuk mendapatkan akses masuk ke dalam course yang ada harus memiliki access code. Penggunaan access code secara default bersifat terbuka, artinya siapa saja yang memiliki access code bisa langsung masuk ke dalam course yang sudah dibuat. Namun, untuk menghindari adanya doubleuser atau adanya user yang tidak diinginkan maka bisa menambahkan feature require approval.

c. Menambahkan Materi dengan Course Material

Course material adalah bagian inti dari sebuah proses belajar mengajar. Pada course material inilah tempat untuk membuat berbagai macam kebutuhan dalam proses belajarmengajar. Terdapat beberapa bagian pada course material yakni: 1) Assignments 2) Tests/Quizzes, 3) Files and Links, 4) External Tools, 5) Discussions, 6) Pages, dan 7) Media Album. Ketujuh feature ini bisa digunakan untuk meunjang segala aktifitas dosen untuk mengajar dan memberikan penilaian. Dosen/guru dapat membuat tugas bagi mahasiswa pada schoology, dengan memanfaatkan tombol AddMaterial yang ada di bagian atas Course Material, kemudian klik Add Assignment. Sebelum membuat Assignment dosen/guru juga bisa membuat folder terlebih dahulu untuk merapikan tampilan pada Course Material. 


\section{Penutup}

Berdasarkan penjelasan yang disebutkan pada bagian sebelumnya, tulisan ini menyimpulkan bahwa: 1) Kurikulum 2013 edisi revisi 2017 untuk tingkat SMA telah memuat konten pembelajaran sastra yang sesuai dengan porsinya. Melalui konten materi tersebut, diharapkan guru bahasa dan sastra Indonesia dapat mengembangkan materi ajar sastra tersebut ke arah pembelajaran apresiasi sastra, dan 2) Inovasi pembelajaran apresiasi sastra dapat dilakukan dengan memanfaatkan internet dalam bentuk pembelajaran blanded learning menggunakan portal schoology.

\section{Daftar Pustaka}

Andayani. (2009). Bahasa Indonesia. Surakarta : Panitia Sertifikasi Guru (PSG) Rayon 13 Surakarta.

Heinze, A. (2008). Blended learning: An interpretive action reseach study. Disertasi doktor, tidak diterbitkan, University of Salford, Salford, UK

Tyasititi, dkk. 2014. Pelaksanaan Pembelajaran Apresiasi Sastra Kelas VII Smp Akselerasi. BASASTRA Jurnal Penelitian Bahasa, Sastra Indonesia dan Pengajarannya. Volume I Nomor 3, April 2014.

Oemar Hamalik, (2003). Kurikulum dan Pembelajaran. Jakarta: Bumi Aksara.

Rusman. 2012. Model-Model Pembelajaran. Jakarta: Grasindo

Permendikbud Nomor 73 Tahun 2013

Permenristekdikti Nomor 44 Tahun 2015 